\title{
Gender considerations along the HIV treatment cascade: An evidence review with priority actions
}

Melanie Croce-Galis

Jill Gay

Karen Hardee

Population Council

What Works Association

Population Council

Follow this and additional works at: https://knowledgecommons.popcouncil.org/departments_sbsr-rh

Part of the Demography, Population, and Ecology Commons, Family, Life Course, and Society Commons, International Public Health Commons, and the Women's Health Commons How does access to this work benefit you? Let us know!

\section{Recommended Citation}

Croce-Galis, Melanie, Jill Gay, Karen Hardee, What Works Association, and Population Council. 2015. "Gender considerations along the HIV treatment cascade: An evidence review with priority actions," Treatment brief. Washington, DC: The Evidence Project. 


\title{
GENDER CONSIDERATIONS ALONG THE HIV TREATMENT CASCADE:
}

\author{
AN EVIDENCE REVIEW WITH \\ PRIORITY ACTIONS
}

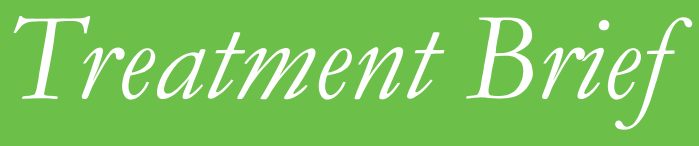

Melanie Croce-Galis, ${ }^{1}$ Jill Gay, ${ }^{1}$ and Karen Hardee ${ }^{2}$

${ }^{1}$ What Works Association, ${ }^{2}$ Population Council

Photo credit: 2006 Mike Wang/PATH, Courtesy of Photoshare

\section{Introduction}

Evidence, including the recent findings of the START study, shows the overwhelming success of early HIV treatment in lowering the risk of developing AIDS as well as preventing HIV transmission. ${ }^{2}$ Access to antiretroviral therapy (ART) has improved significantly in recent years. At the end of 2013, there were 12.9 million people receiving ART, with 5.6 million of those added since $2010 .{ }^{3}$ Nonetheless, at the end of 2013 only $37 \%$ of people living with HIV were receiving treatment, leaving 22 million people in need of ART. ${ }^{4}$ In 2014, UNAIDS set the 90-90-90 target - an "ambitious but achievable" goal toward ending the AIDS epidemic by 2030 (see Box 1).

The 90-90-90 target focuses on equity; UNAIDS notes "it will be impossible to end the epidemic without bringing HIV treatment to all who need it." 5 This brief demonstrates how gender dynamics impact HIV treatment access and adherence and illustrates how greater attention to these dynamics within HIV interventions can improve treatment uptake and adherence critical to achieving the 90-90-90 goal. This brief uses WHO's HIV care cascade as a useful framework within which to view the evidence regarding how gender dynamics help or hinder HIV treatment efforts (see Figure 1). This brief also identifies priority actions needed for gender-equitable treatment programming to achieve

\section{About this brief}

This brief provides policymakers and program implementers with evidence about the impact of gender dynamics on treatment access and adherence and the gender-related gaps in treatment research and programming. It also includes priority actions that can be taken to better address gender within treatment programming and raises questions for implementation science in order to achieve the global 90-90-90 goals (see Box 1). This brief draws from What Works For Women and Girls: Evidence for HIV Interventions (www.whatworksforwomen.org) and uses the WHO treatment cascade framework to identify and analyze major gender considerations in providing antiretroviral therapy to those living with HIV in low- and middle-income countries. It focuses on antiretroviral treatment access and adherence as well as the gender dynamics related to who gets tested and under which circumstances. The brief does not cover the full provision of "HIV care" defined in the cascade to also include prevention, detection and treatment of co-infections such as TB, as well as nutrition and social support. ${ }^{1}$ For more on gender dynamics within those topics and to read about the full methodology for the evidence review, please see www. whatworksforwomen.org. 


\section{Box 1}

\section{0-90-90 Target}

By 2020:

- $90 \%$ of all people living with HIV will know their HIV status.

- $90 \%$ of all people with diagnosed HIV infection will receive sustained antiretroviral therapy.

- $90 \%$ of all people receiving antiretroviral therapy will have viral suppression.

Source: UNAIDS, 2014

the 90-90-90 goal. Given that there are few evaluated gender interventions for HIV treatment, these priority actions, along with additional questions for implementation science, are based on programmatic and technical expertise, as well as a review of the literature. The actions can be carried out at multiple levels such as at the community, clinic and policy levels and, though far from a comprehensive list, illustrate how a gender lens can be useful in ensuring equity in treatment access and adherence. Further dialogue, research, programming, and importantly - evaluation - is needed with input from multiple stakeholders.

\section{Gender Dynamics within the Care Cascade}

\section{Knowing One's HIV Status}

There are often gender differences in who gets tested and why. A review of the literature on studies conducted in rural India from 1980 to 2008 found that men sought testing because they were personally concerned, whereas women sought testing upon the recommendation of their antenatal provider - and in some cases reported mandatory testing by their provider. ${ }^{6}$ Most women access HIV testing within maternal health services. Since they come into contact with the health system regularly, pregnant women are disproportionately tested for HIV. ${ }^{7}$ A 2009 study in rural Mozambique found that HIV testing in non-pregnant women was "uncommon." ${ }^{8}$ The emphasis on counseling and testing for prevention of maternal to child transmission (PMTCT) means that women who are not pregnant are inadequately reached with HIV testing and counseling services.

Women must navigate a number of hurdles in accessing testing. Many women, especially rural women, are unable to afford the time or money required to travel to a facility providing HIV testing. In some places, high rates of illiteracy mean that many women cannot access written information about the benefits or availability of HIV testing. Stigma, gender inequalities, and fear of negative outcomes following disclosure are significant barriers. Such outcomes include moral judgment and blame; ostracism by household or community; relationship termination; verbal and/or physical abuse as well as discrimination. In many countries, women living with HIV are spoken of as being promiscuous women who deserve this disease as a punishment for their sins. ${ }^{9}$ Fear of stigma and discrimination from health care providers is also a concern, especially for women from marginalized groups such as those who are sex workers or transgender.

\section{Gender Norms Affect Men As Well as Women}

Men, too, must overcome barriers to testing. A study in Lesotho found that there was better access to testing for women and a strong fear of testing among men. ${ }^{10}$ Global attention has focused often on prevention of vertical transmission, ${ }^{11}$ putting men simply in the role of supporting access to services for their female partners living with HIV, rather than caring for their own needs. In

\section{FIGURE 1}

\section{HIV Care Cascade}

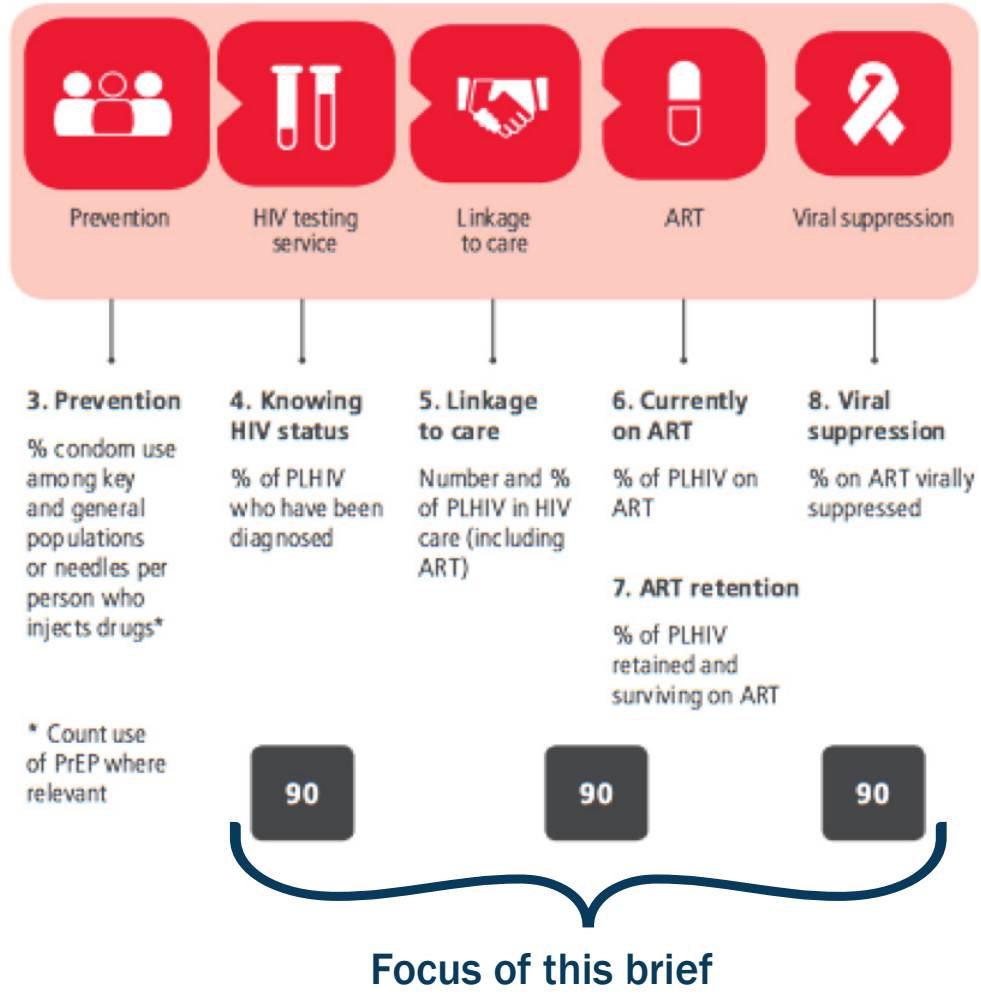

Source: WHO, 2015 


\section{Box 2}

Why is sex-and age-disaggregated data important?

\section{Because it helps identify gaps in treatment} programming.

For example, of 10,000 people on treatment in Malawi (Makwiza et al., 2008):

- More men than women accessed treatment in the 15-19 year age group, yet HIV prevalence in this age group was higher among women.

- More women than men accessed treatment in the 30-39 year age group, yet HIV prevalence was higher among men in this age group.

Without sex- and age-disaggregated data, these inequities are masked under one number: " 10,000 on treatment" and critical programming gaps would remain unnoticed.

many areas of the world, HIV is seen as a threat to a man's masculinity, "requiring him to seek care, challenging his notions of fearlessness, and fueling fears of humiliation and that his wife will desert him."'12 Men also may worry that they acquired HIV from extramarital partnerships and may therefore be less likely to disclose their HIV-positive serostatus to their spouse ${ }^{13}$ or to want to get tested in the first place.

A study in South Africa-where counseling and testing for HIV is most frequently accessed in antenatal care settings and a few stand-alone centers ${ }^{14}$ — found that men rarely initiate discussions with their female partners concerning HIV testing and mostly relied on female partners to test as a means of determining their own HIV status, not understanding that sexual partners who are serodiscordant can exist. ${ }^{15}$ Focus group discussions with young men in Malawi and Uganda found that gender norms, such as equating masculinity with invulnerability and sexual conquest, were the reasons they would not access HIV testing and counseling. ${ }^{16}$

Addressing gender norms that suggest that 'real men do not get sick' will be critical to increasing HIV testing and counseling by men, as well as creating more opportunities for men to get HIV testing and counseling. ${ }^{17}$ Rapid expansion of testing, however, without ensuring informed consent and confidentiality could increase the risk of women and transgender people being rejected by their families, losing their property, and suffering violence and abuse. As noted by Jürgens and Cohen, "efforts to increase access to HIV testing must be accompanied by vastly scaled up efforts to confront the stigma and human rights abuses that deter people from seeking HIV tests in the first place...." 18

\section{Priority Actions for Programming and Policy}

- Expand coverage to reach more women

- Expand coverage of HIV testing and counseling both within and outside of antenatal care settings.

- Link ART services with gender-based violence services

- Strengthen referral programs for testing and ART services with services for gender-based violence.

\section{- Reach men}

- Promote campaigns that counter the harmful gender norm that "real men don't get sick"; promote positive images of men using health services for the benefit of themselves, their partners, and their families.

- Create programs to reach men as independent users of health services rather than exclusively through their female partners, both for testing and for treatment

- Create testing programs for male clients of sex workers with linkage to treatment.

\section{- Strengthen couples testing}

- Revise national and local guidelines to include a context-appropriate definition of a "couple," gender-sensitive ways to engage men and women in counseling, and linkages to available gender-based violence services, when needed.

\section{- Reach youth}

- Create opportunities for testing with linkage to treatment services in schools and universities in order to reach young men and young women prior to their first pregnancy.

\section{Questions for Implementation Science}

- How can the number of men as users of health services - particularly for testing and treatment - be increased?

- How can stigma be reduced to encourage greater uptake of HIV testing? 


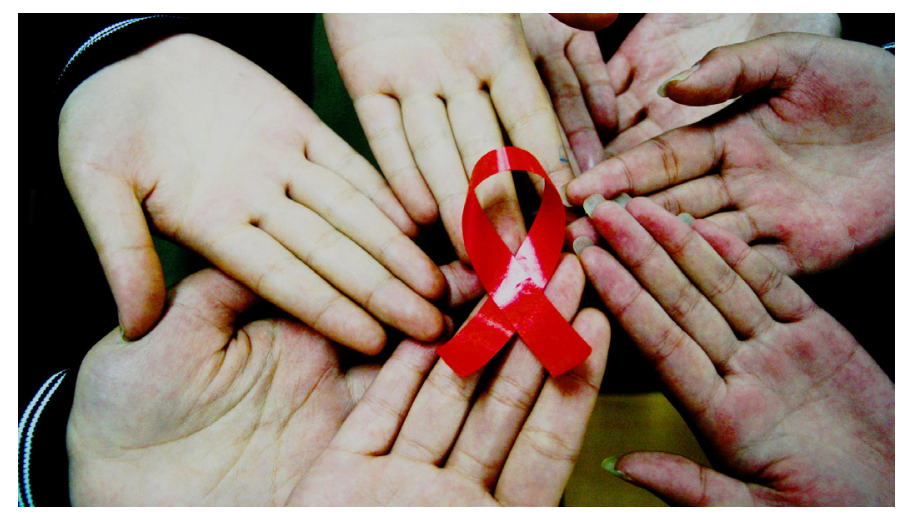

(C) 2015 Uppili Venkat Ragavan, Courtesy of Photoshare

\section{Enrollment in ART \& Treatment Care*}

Gender norms affect treatment access for men and women. Women constitute a higher proportion of those receiving ART than men. For all low- and middle-income countries, women constitute $51 \%$ of those eligible for care but make up $59 \%$ of those receiving ART. ${ }^{19}$ However, while more women than men have accessed treatment globally, structural factors and traditional gender norms can jeopardize women's adherence, retention in care or ability to reduce transmission.

"Women are often more likely than men to attend health services because of dedicated provision of reproductive and child health clinics." ${ }^{20}$ Many women are first tested and then put on treatment with the goal of prevention of vertical transmission. But inadequate attention is given to the treatment needs of women outside of this scope. The new WHO guideline recommending Option B+ allows pregnant women living with HIV to remain on treatment for life following their pregnancy. But the word "option" is a misnomer - it is an option for the country, not necessarily for the pregnant women. In a study in Malawi and Uganda, pregnant women were told they could have less than 24 hours to consider whether to go on treatment for life - a weighty decision. As one woman put it: 'T'm 18 years, you are telling me drugs for life?"21 In addition, the focus has been on prevention of vertical transmission, or as one woman living with HIV states: "The doctors say, 'Listen, we are not giving you these ARV s to save you, we are saving the baby....",22 It is not surprising, therefore, that there are high dropout rates from treatment programs postpartum, including Option $\mathrm{B}+.^{23}$ In several countries, Option $\mathrm{B}+$ rollout "has been characterized by high levels of 'loss to follow up' and lower rates of adherence." 24

In addition, male involvement in Option $\mathrm{B}+$ has been

\footnotetext{
* Note that this brief focuses on antiretroviral therapy and does not fully cover all aspects of treatment care such as treating co-infections and provision of nutritional and social support.
}

interpreted in some countries as a requirement that a man be present to access treatment. Some women instead choose to hire men to pose as their male partners: "Because when you go to antenatal you are asked to come with your partner, women have chosen to hire boda boda (motorcycle taxi drivers) to go with them to access the services." ${ }^{25}$ Priority for treatment access to pregnant women creates problems within relationships: "Actually, the first time I was told about Option B+, the first question I remember I asked was 'what about the man?' W by did I ask this? Because I really saw that there were going to be conflicts of interest because men are going to now say, W Wy women? Aren't we also human beings?'” Or as another woman put it: "Men will say, It's me who made that woman pregnant. Why am I not started on treatment too?'”26

\section{Men Often Enroll in ART Later than Women}

The Institute of Medicine notes that for PEPFAR data, each year there were more initial enrollments in ART among women than among men; the proportion has remained steady over time at about $65 \%$ of women and $35 \%$ of men. This imbalance is greater than the difference in HIV prevalence between men and women. ${ }^{27}$ Patient data from 307,110 adults from Kenya, Mozambique, Rwanda and Tanzania between 2006 and 2011 found that risk of late enrollment (CD4 counts under 350) was significantly higher for men and nonpregnant women as compared to pregnant women. ${ }^{28}$

Harmful gender norms (e.g., viewing seeking health care as weakness) frequently cause men to delay presentation for treatment, which can reduce their life expectancy. A study of 4,775 patients from Uganda found there was a higher death rate for men, even when the analysis included women who accessed ART outside of ANC services, with more men presenting for care with lower CD4 counts, with single men having significantly lower CD4 counts than married men or single women. ${ }^{29}$

“...Although women remain more vulnerable to HIV infection, once infected, men tend to be disadvantaged in 
terms of access to treatment and care." In many countries, men initiate treatment later, are more likely to be lost to follow up, and have higher mortality rates. ${ }^{30}$ Focus group discussions with men in Uganda found that men found it difficult to seek treatment, which contradicted their assumed masculine autonomy and superiority. ${ }^{31}$

A global review based on 36 studies in resource-rich and resource-limited settings found that being a heterosexual male was a consistent risk factor for presenting with low CD4 counts, resulting in less favorable outcomes for men once enrolled in treatment. ${ }^{32}$ In South Africa in 2011, the fraction of ART-eligible women who were receiving ART $(65 \%)$ was significantly higher than the fraction of ARTeligible men who were on treatment $(41 \%) .{ }^{33}$ An analysis of 23 cohort studies from Africa, including 216,008 participants found that only $35 \%$ of those accessing ART were men, despite an HIV prevalence of $40 \%$, representing "a significant underrepresentation of men in ART programs." ${ }^{34}$ In addition, the risk of death for men was 1.37 times higher than for women. ${ }^{35}$ However, men are seldom targeted as they are not often classified as vulnerable or marginalized. ${ }^{36}$ While this inequitable access for men to ART may be due, in part, to a focus on maternal health, equitable access to ART for men "should be conducted without ...threatening HIV ...treatment for women." 37

A study of sex differentials in ART uptake in Zambia found that men were more likely to refuse ART even though men's self-rated health was lower than women's, with norms of masculinity presenting the biggest barrier for male uptake of ART. ${ }^{38}$ Other studies have found that men who received treatment ${ }^{39}$ were more likely to die than women because of late presentation for treatment or were frequently lost to follow up..$^{40}$ A study of programmatic data on 334,557 adults enrolling in HIV care at 132 facilities in Kenya, Mozambique, Rwanda and Tanzania found that men were 1.6 times more likely to initiate ART with advanced HIV disease (CD4 count under 100) compared with women and that "this disparity seems to be widening...."41 A recent study found that men used their economic and decisionmaking power to informally access ART in order not to be seen at clinics, which are seen as a woman's space. Out of shame, men suffered silently and attempted to cope by stealing their wives' ARVs. The practice of men stealing ARVs from their wives endangers both partners, jeopardizing women's adherence. ${ }^{42}$

Gender norms of female submissiveness and women as caretakers may be critical also for the higher uptake of ARVs by women, as explained by one Vietnamese woman living with HIV: "Women have no choice but to take the drugs.
Meanwhile, men are the ones who consider whether or not to take the drugs because they don't need to think of anything else except themselves. ${ }^{\prime 3}$ Greater attention needs to be paid to ensuring that men living with HIV know their serostatus, have access to condoms, understand the need for consistent and correct condom use, and have equitable access to treatment. "Closing the coverage gap in men needs to be a priority to tackle health-related gender inequalities, improve overall health in men, and decrease transmission...." 44

\section{Inequitable Access to ART Also Differs by Age and Social Status}

Some studies have found that equity in access differs by age group with inadequate treatment access for adolescent women. In Malawi, for example, of 10,000 people on treatment, proportionately more women accessed treatment than men. However, in the 15 to 19 year age group, more men were proportionately on treatment despite the fact that HIV prevalence in this age group was higher among women. ${ }^{45}$ "Despite the growing number of older children and adolescents who develop symptoms, there has been little focus on providing this group with specialized HIV care." ${ }^{46}$ Providers need training to provide nonjudgmental care. Instead, one study found that providers would say to adolescents living with HIV: "You are HIV-positive. You are not expected to have sex. You are not expected to have a baby.',47

Transgender people are marginalized and subject to stigma, violence and social exclusion, ${ }^{48}$ which can affect treatment access and adherence. Similarly, sex workers - who are, worldwide, mostly women ${ }^{49}$ and among the most marginalized of women ${ }^{50}$ - face barriers in accessing treatment due to stigma, discrimination and social exclusion. ${ }^{\dagger}$ Importantly, WHO notes that key populations should have the same access to ART and care and the same ART management as other populations, "[h]owever, because of stigma, discrimination and marginalization, they frequently present late for treatment." 51 Thus, ART programming that respects human rights is critical - for key populations, as for all.

\section{Priority Actions for Programming and Policy}

\section{- Strengthen services}

- Ensure that all service providers are trained in the principles of non-discrimination to ensure that people of different gender identities can access quality services with respectful treatment, counseling and support.

$\dagger$ While transgender issues are raised throughout this brief, a full discussion of the barriers to treatment by sex workers, people who use drugs and other key populations is beyond the scope of this brief. 
- Identify avenues to provide treatment to women outside of antenatal care services to reach women who are not pregnant.

\section{- Reach men}

- Create both an inclusive atmosphere as well as physical space within clinics where men can initiate ART with follow up within communities and with male peer support.

\section{- Reach youth}

- Create services that will reach adolescent girls living with HIV, particularly those under age 18 who will not be reached through pediatric services yet are not comfortable in adult settings.

- Create sustainable adolescent friendly HIV services that also meet reproductive health needs.

\section{- Review data}

- Analyze HMIS data on an ongoing basis to assess gender equitable access, adherence, and retention to ensure that care and treatment services are reaching people in proportion to the burden of the epidemic.

\section{Questions for Implementation Science}

- How can men's engagement with health and ART services be fostered without interfering with women's decision-making and autonomy?

- How can treatment programming reach those who have not yet been reached?

\section{ART Retention}

For the most part, men and women have similar ART adherence rates. But there are gender differences in predictors of adherence. Women may need family support, including redistribution of household responsibilities, to enable them to adhere to treatment. Even if drugs are free or subsidized, women may not be able to afford the time or money required to travel to a clinic. A qualitative study of women living with HIV in Colombia found that women prioritized the needs of their HIV-positive children over their own adherence needs. ${ }^{52}$ Women in Malawi and Uganda also reported financial and other challenges in managing their own adherence as well as that of their children. ${ }^{53}$ Some women sold their ARVs for economic survival. ${ }^{54}$ Women may also have difficulty navigating treatment when it conflicts with other activities for survival. Sex workers, in particular, face difficulties in adherence in large part due to stigma and discrimination. One South African sex worker points out the struggles she faces: "If you don't pay off the police, they take you to jail... you can't take antiretroviral drugs or any medication you need. ${ }^{155}$ Female sex workers in Vietnam reported that they were not allowed to join networks of people living with HIV who gained access to valuable support and information services because they were seen as "social evils" rather than "innocent wives getting the disease from their husband." 56

\section{Other Life Activities Affect Women's Adherence}

Pregnancy represents an additional sex-related factor in treatment. In a study of 4,531 women from numerous treatment sites in Sub-Saharan Africa, one-third experienced a pregnancy within four years of ART initiation. ${ }^{57}$ Yet few treatment programs are designed with the likelihood of pregnancy in mind. ${ }^{58}$ Most of the world's women living with HIV are of reproductive age and will need either contraception or discussions on how to become pregnant while reducing the risk of HIV transmission to their infants and/or partners.

Side effects can also deter women from adhering to treatment plans. Some medications cause a redistribution of body fat resulting, for example, in a large belly, or a collection of fat at the base of the neck, or loss of fat from the cheeks. ${ }^{59}$ Women have reported problems with adherence due to how ARVs changed their appearance, with bodily changes creating visibility of their HIV-positive serostatus and consequent stigma. Women may also be more adversely affected by the common side effects of ARVs that result in anemia. ${ }^{60} \mathrm{~A}$ study of quality of life among people living with HIV in Cuba found that pain interfered more in women's lives than in men's lives, and that women did not enjoy the same health-related quality of life as men. ${ }^{61} \mathrm{In}$ Vietnam, men, even if they injected drugs, reported better quality of life on antiretroviral therapy than did women, as women cared for the men. ${ }^{62}$

\section{Men's Sense of Masculinity Can Affect Treatment Adherence}

Men also face particular challenges in accessing and adhering to HIV treatment. Men's ideal sense of masculinity may be threatened by "disclosing their HIV status and seeking treatment in fear that they would be perceived as failing sons, husbands or breadwinners...." ${ }^{63}$ A study of men in Uganda found that adherence challenged gender norms of masculinity, with men reporting that nurses scolded them: "It involves being shouted upon like a child, don't you see, no respect at all. ${ }^{764}$ Being physically strong, capable of hard work and having children were also seen as signs of masculine identity, which were threatened by being labeled HIV-positive. A study from South Africa found that men's adherence was challenged by employment, with problems getting time away from work for clinic visits or loss of income due to waiting in clinic lines. ${ }^{65}$ 
Treatment may be undertaken by some men to regain health and self-worth with the ability to work and provide for their families as a sign of their masculinity. ${ }^{66}$ In one South African study, when men were not yet on ART but diagnosed with HIV, family members withdrew support and care, as family members feared acquiring HIV. Once on ART and feeling physically well, men felt prepared to withstand potential rejection as well as confident to look for a girlfriend if a partner rejected them for their positive serostatus. ${ }^{67}$

Support groups and counseling for men may also be beneficial and men do request them. ${ }^{68}$ Focus group discussions in South Africa with men living with HIV on treatment who had disclosed to their partners found that they wanted to access male-only support groups with guarantees that their HIV status would not be disclosed outside of the support group setting. Despite the fact that support groups were available four times per week, men did not know of these support groups, ${ }^{69}$ which met at clinics where they collect their medication. In Uganda, men who were recipients of financial support, such as expenses for children's education or given livelihood options, such as goats, were more adherent than men without this support. ${ }^{70}$

\section{Stigma and Gender Norms Can Make Efforts to Encourage Retention and Reduce HIV Transmission Difficult}

Non-judgmental, non-stigmatizing interventions both within the health sector and outside the health sector, such as transforming gender norms, reducing violence against women, revising laws that criminalize non-disclosure of HIV, to name a few, ${ }^{71}$ need to be implemented in order to support safer sexual behavior once someone knows his or her positive serostatus.

Some serodiscordant couples identify fear of transmission as a primary concern in their relationships or fear the impact that disclosure will have on the HIV-negative partner. ${ }^{72} \mathrm{~A}$ study in South Africa found that among 413 men living with HIV and 641 women living with HIV, stigma and discrimination was associated with non-disclosure and that non-disclosure was associated with HIV transmission risk behaviors. ${ }^{73}$

"Persistent rates of nondisclosure by those diagnosed with HIV raise difficult ethical, public health and human rights questions about how to protect the medical confidentiality, health and well-being of people living with HIV on the one hand, and how to protect partners and children from HIV transmission on the other." ${ }^{, 74}$ Criminalization of transmission and nondisclosure undermines rights while serving little public health benefit, but gender issues are key
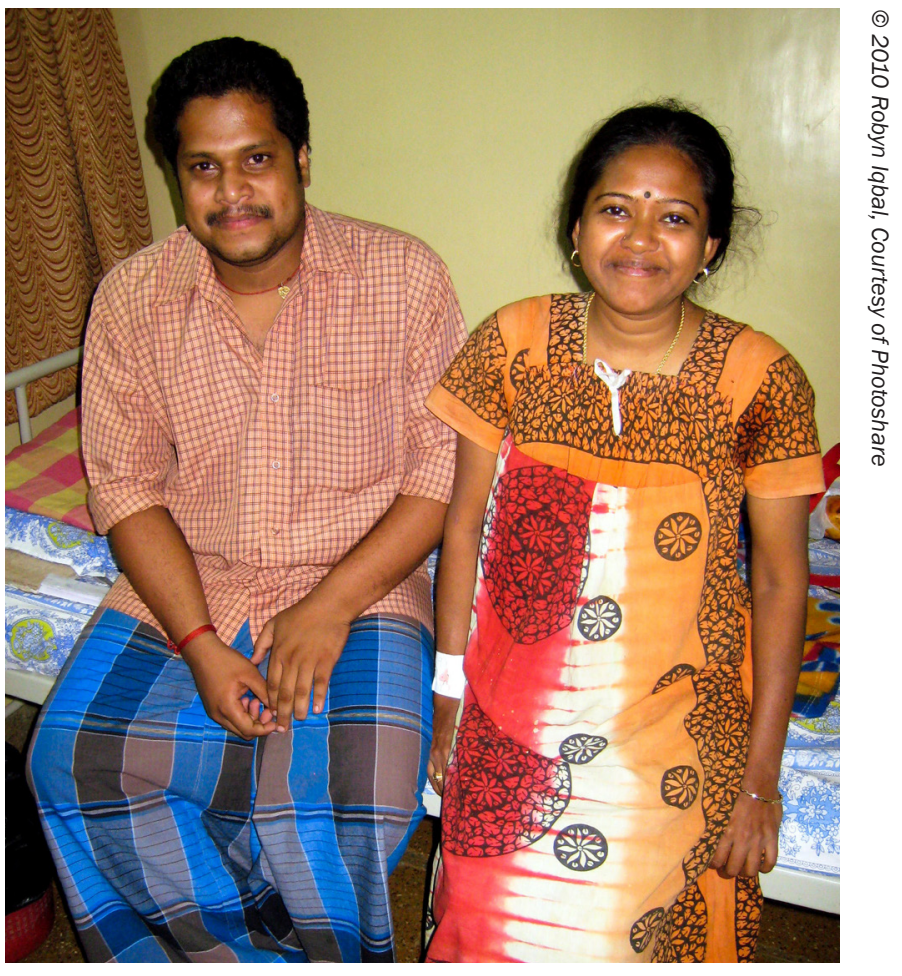

to HIV disclosure. ${ }^{75}$ Because women are tested for HIV at much higher rates than men, any approach that blames women living with HIV for not disclosing their status will disproportionately burden women. Where male partners have been unwilling to get tested for HIV, some women living with HIV did not feel an obligation to disclose their positive serostatus. ${ }^{76}$ Women "reflected upon the fact that men seemed unwilling to test but preferred to blame their female partners." 77 In some cases, women are significantly less likely to know their partner's status than men. ${ }^{78}$ And one study of women living with HIV in South Africa found that consistent condom use was not correlated with disclosure to either HIV-negative or HIV-positive male partners. ${ }^{79}$ For women living with HIV, "it is ultimately the decision of the man to either use a male condom or not," ${ }^{80}$ with gender norms on sexuality key to male use of condoms. Some evaluated interventions exist regarding women's use of female condoms in the absence of male condom use. However, " ... limited access to female condoms and substantially higher costs have limited uptake and use of female condoms," ${ }^{\prime 1}$ thus limiting an opportunity to reduce HIV infection through a woman-initiated prevention method.

Transgender people can face a double stigma for their gender as well as for their positive serostatus, making accessing needed health and HIV services, which usually operate on strict male/female gender identities, extremely difficult. They are often overlooked in HIV treatment programming. 


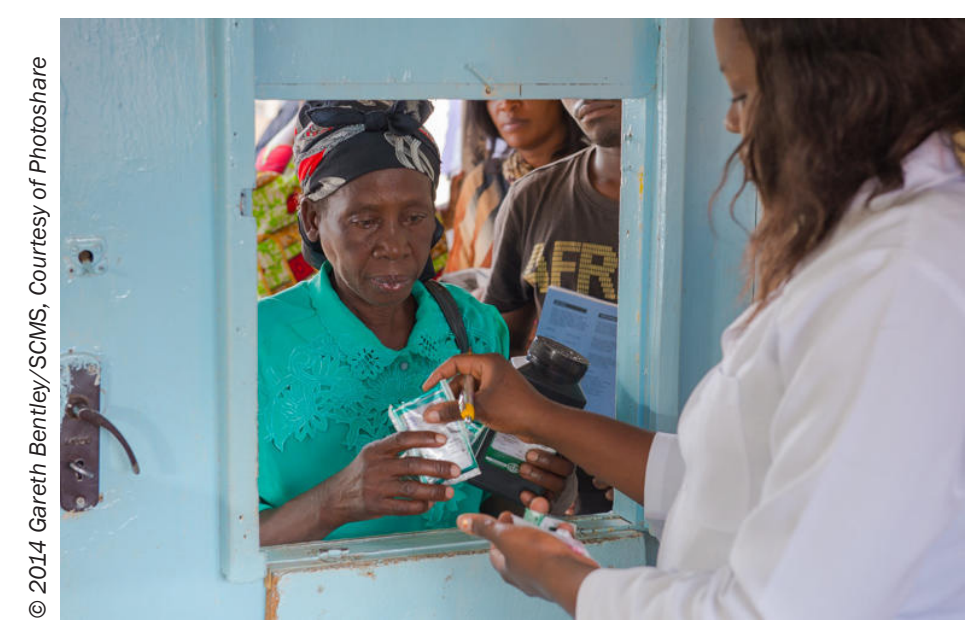

\section{Fear of Disclosure Impacts ART Retention and Transmission Reduction Efforts}

Disclosure is not a one-time event but a process calling for careful consideration as to whom to disclose and when. A study in Zimbabwe of 200 women living with HIV on ART found that $96.5 \%$ disclosed to at least one person, most frequently their sister. ${ }^{82}$ Both women and men need to learn how to negotiate safe sex prior to disclosure, knowing when to disclose and how to disclose. Women in one study noted that once they disclosed, no man had stayed with them..$^{83}$ In another study in Uganda, "the need to provide for children was a particularly strong motivation for women to avoid disclosure," $" 84$ as men abandoned or abused partners who disclosed or requested condom use. One cross-sectional survey in Cameroon found that women living with HIV who were not financially dependent on their male partners were much more likely to have used condoms, ${ }^{85}$ suggesting the importance of the enabling environment.

A study in South Africa found that for men, disclosure undermined their sense of masculinity as health-seeking would portray them as weak and dependent, as well as subject to control by health care providers, noting that "men believed that 'real men' deal with personal problems on their own, instead of asking help from other people." ${ }^{\prime 86}$ However, once on ART, men's health and appearance improved and they felt publicly able to share their HIV-positive serostatus, which in turn won them support, approval and admiration, becoming role models for breaking the secrecy and stigma surrounding HIV. ${ }^{87}$ Other studies found that men were particularly critical of serodiscordant couple interventions, as couples counseling puts "the man on trial." As one man put it: "It is as if you are before a court, as you know women can get authority over the man when other people are there... So your wife may ask you how the disease came about. So you have to reveal the extra affairs.... ${ }^{\prime 88}$ Providing sex-segregated counseling may be more effective. ${ }^{89}$

\section{Priority Actions for Programming and Policy}

\section{- Provide information and support}

- Within all treatment programs, counsel both men and women on their options if they want to become pregnant/have a child or avert unintended pregnancies.

- Create sex-segregated ART support groups, similar to the mothers2mothers model for pregnant women, for all who are living with HIV.

- Strengthen training for counselors and other healthcare workers providing guidance on safe disclosure for both men and women (separate guidance for each, address gender issues for each).

- Provide services that are user-friendly such as with on-site childcare or at times or locations that are women- men- and family-friendly.

\section{- Address legal barriers}

- Create or strengthen programs for the judicial sector to ensure ART is available within jails, prisons, etc. and that those living with HIV taken into custody can adhere to ART. (This is particularly important for sex workers).

- Decriminalize HIV transmission, which can be particularly harmful to women and may criminalize vertical transmission during pregnancy.

\section{- Analyze gender dynamics}

- Review and design programs to ensure that they are based upon a gender analysis and address harmful gender norms and gender-based violence and are evaluated to better elucidate how a gender-sensitive approach affects treatment adherence and retention.

\section{Questions for Implementation Science}

- How can peer support be effectively provided for men and how does it differ from a peer support model for women?

\section{Viral Suppression}

ART adherence is critical to achieving viral suppression. Additional factors such as drug resistance, drug interactions and biological differences may also be subject to genderrelated challenges in achieving viral suppression.

Women may be at greater risk for viral drug resistance or transmitting drug resistant strains due to the temporary use of antiretrovirals to reduce vertical transmission. Further evaluation is needed to understand these risks. While it is 
clear that those who go on ARV therapy for their own treatment needs should not interrupt treatment, ${ }^{90}$ treatment interruption for women who are on ART to prevent perinatal transmission rather than for their own health needs is the subject of an ongoing clinical trial (PROMISE), with results expected in 2017. "The risk for maternal health of stopping... maternal triple ARV prophylaxis after breastfeeding cessation is unknown" a woman living with HIV has multiple pregnancies. WHO recommendations for Option B+, i.e., lifelong treatment for pregnant women, may reduce stopping and re-starting ART which can carry increased risk for mortality and morbidity.

Monitoring drug interactions can be increasingly complex in populations that may also be using drugs for co-infections, co-morbidities, or recreationally. Cross-hormonal treatment protocols for transgender women and men may affect HIV treatment success. While there are currently no documented drug interactions among these medications and ARVs, further research is needed. ${ }^{92} \mathrm{It}$ is possible that ART may lead to hormonal fluctuations and metabolic abnormalities among transgender women taking hormonal medications and close monitoring is needed. ${ }^{93}$

\section{There May be Sex Differences in ART Efficacy}

Access to treatment by sex has been disaggregated in a number of studies. However, few studies have analyzed sex differences. Studies to date have not shown differences in virologic efficacy of ART by sex, ${ }^{94}$ although a number have suggested that sex may influence the frequency, presentation, and severity of selected ARV-related adverse events. ${ }^{95}$ One study found differences in virologic failure (i.e., ART fails to suppress and sustain viral load to less than 200 copies/mL) by sex, with women having an advantage over men. ${ }^{96}$ Another study found that women were more likely to have viral suppression and better ART outcomes ${ }^{97}$ while other research found that women were in better clinical condition than men. "Although data are limited, there is evidence that women may metabolize and respond to specific medications, including ARV drugs, differently than men." ${ }^{99}$ In some studies, however, women experience more adverse drug reactions than men. ${ }^{100}$

d'Arminio Monforte et al., 2013 notes “[a]lthough published data suggest that there are no significant differences in ART efficacy between women and men, it must be emphasized that this is a conclusion drawn from a limited evidence base." 101 ARVs are administered at fixed dosages that do not take into account the different body weight, etc. of each sex. ${ }^{102}$ A study in Tanzania in which $70 \%$ of the 234 patients were women found that after one year of standard ART, a higher proportion of females had an undetectable viral
Box 3

\section{Results to Watch for}

A number of ongoing efforts are looking at gender dynamics in HIV treatment. Major initiatives with results to watch for include:

- Key Barriers to Women's Access to Treatment: Making 'Fast-Track' a Reality: This collaboration of UN Women, ATHENA Network, AVAC, and Salamander Trust is undertaking a global multi-stage review of the status of access to antiretroviral therapy for women living with HIV that includes a literature review, community dialogues and country case studies. Expected late 2015.

- Supporting Operational AIDS Research (Project SOAR): Population Council and partners are determining whether a community mobilization intervention can effectively change gender norms at the community level, and whether reductions in harmful gender norms contribute to better health service utilization, in particular services along the HIV care and treatment continuum. Expected 2018.

- STRIVE Research Consortium: A six-year consortium investigating the social norms and inequalities that drive HIV, including: gender inequality and violence, poor livelihood options, alcohol and drinking norms and stigma and considerations. Ongoing projects are taking place in India, South Africa and Tanzania through 2018.

- Accelerating Children's HIV/AIDS Treatment Initiative (ACT): U.S. President's Emergency Plan for AIDS Relief (PEPFAR) and the Children's Investment Fund Foundation (CIFF) launched this two-year initiative to double the number of children receiving ART across ten priority African countries. Expected 2016.

load but with less of a CD4 cell increase than men. Women started treatment at a less advanced disease stage but women lost their immunological advantage over men despite a better virological treatment response. In addition, men were better informed about the use of ART. ${ }^{103}$ Other studies have found that men are disadvantaged in ART due to differences in body weight compared to dose. ${ }^{104}$

The potential role of sex differences in HIV disease progression and treatment response is an understudied area of inquiry, ${ }^{105}$ with women under-represented in clinical trials. ${ }^{106} \mathrm{~A}$ review of forty randomized controlled trials for 18 new drug applications for antiretroviral therapy submitted to the U.S. Food \& Drug Administration (FDA) between 


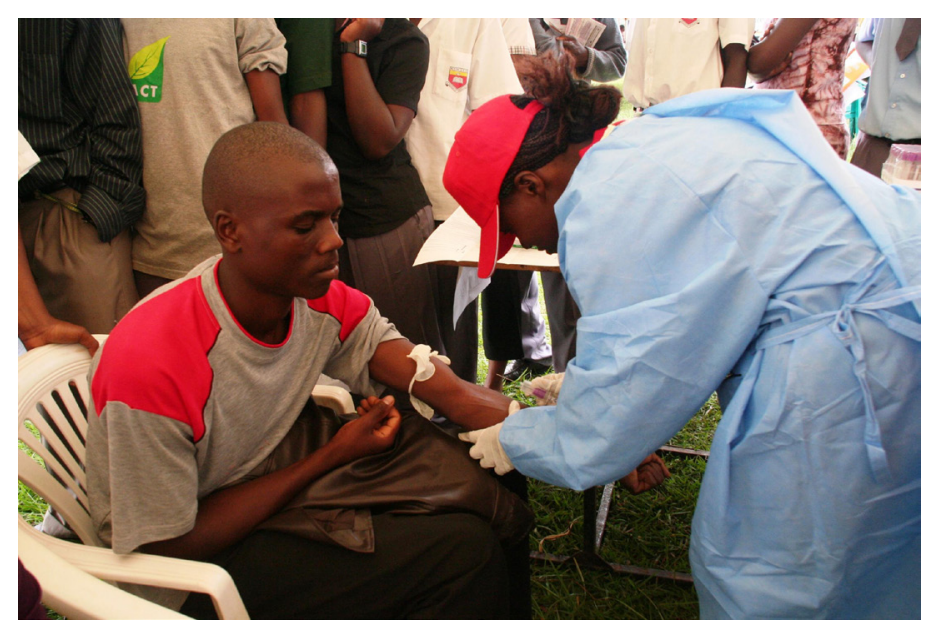

(C) 2012 Uganda National Volunteers Link, Courtesy of Photoshare

2000 and 2008 found that only $20 \%$ of trial participants were women. ${ }^{107}$ Even when women are included, sexspecific analysis of the data is rarely undertaken. ${ }^{108}$ No studies have addressed the possible interactions between ART and sexual hormones in both men and women, including pre, peri or post-menopause. ${ }^{109}$ At a minimum, "research data should be disaggregated by sex to ensure opportunities for [sex- and] gender-based analysis...."110

\section{Priority Actions for Implementation Science}

\section{- Analyze gender and sex differences in clinical} data

- Enroll more women in clinical trials and conduct more gender analyses of the data in order to identify potential sex differences in antiretroviral efficacy and in ART impact on cardiovascular and other noncommunicable diseases affecting those living with HIV.

- Carry out further research on the effect of ART on hormonal medications and vice versa.

\section{Above All, ART Programming Must Include Respect for Human Rights}

Expanding access to ART while considering equity and human rights is urgently needed. ${ }^{111}$ WHO's 2013 guidelines note "human rights and ethical principles should guide... national treatment policies to ensure that they are equitable and meet the specific needs of all beneficiaries." ${ }^{\text {"12 }}$ Requiring people living with HIV to disclose their serostatus to sexual partners and/or community members in order to receive treatment, care or support is a human rights violation. Similarly, coercing women to accept contraception in order to access treatment violates women's rights to make their own fertility choices. While "treatment buddies" can be supportive, requiring a treatment buddy or medical companion to access ARV therapy may place undue burdens on women and their children: a study of 1,453 patients in Uganda on the impact of requiring patients to disclose their HIV status and have a "treatment buddy" or "medical companion" to access ARV therapy found that $41 \%$ of the women chose a child as their medical companion versus $14 \%$ of the men. Individuals with limited networks may delay enrolling in or may drop out of care when treatment support "buddies" are required. ${ }^{113}$

\section{START is Just the Beginning: Moving Forward in Ensuring Gender-Equitable ART}

Given the myriad ways that gender norms impact antiretroviral treatment access and adherence, it is crucial that HIV treatment programming recognize and address gender issues in order to achieve the 90-90-90 goals which seek to increase the numbers of people who know their status, enroll and sustain ART treatment and achieve viral suppression. If gender dynamics are not addressed within treatment programming and policy, efforts to increase treatment coverage will be undermined.

Now that the Strategic Timing of Antiretroviral Treatment (START) study has shown substantially improved outcomes for early treatment initiation, ${ }^{114}$ Kavanaugh et al. argue that states" "core minimum obligations now include access to early ART for both individual and collective benefit. Governments can now reasonably be expected to enable early viral suppression through human rightsbased interventions...."115 These efforts must take into consideration the issue of autonomy that women living with HIV have consistently raised with respect to healthcare decision-making, including whether and when to start treatment. "Despite potential individual and public health benefits for women living with HIV, the decision to begin treatment for HIV is a deeply personal decision that reflects a variety of private, contextual and structural factors." 116

Although there is a growing understanding and documentation of how gender impacts HIV treatment, there remain few evaluated interventions demonstrating what works to overcome these gender-related barriers. A number of questions and concerns remain: how will access to ART be prioritized? How will treatment be financed? How can ART be equitably accessible? How will gender dynamics be addressed in ensuring access? Most importantly, how can ART availability and accessibility be partnered with informed consent about the risks and benefits of treatment so that all people living with HIV may decide for themselves how best to stay healthy and live full, productive lives? 
12. Nyamhanga, T. M., Muhondwa, E. P., \& Shayo, R. 2013. Masculine attitudes of superiority deter men from accessing antiretroviral therapy in Dar es Salaam, Tanzania. Global Health Action, 6, 21812.

13. Anglewicz, P. and J. Chintsanya. 2011. "Disclosure of HIV Status Between Spouses in Rural Malawi.” AIDS Care 23 (8): 998-1005.

14. Mullick, S., M. Menziwa, N. Mosery, D. Khoza and E. Maroga. 2008. Feasibility, Acceptability, Effectiveness and Cost of Models of Integrating HIV Prevention and Counseling and Testing for HIV within Family Planning Services in North West Province, South Africa. Washington, DC: Population Council. www.popcouncil.org.

15. Mindry, D., S. Maman, A. Chirowodza, T. Muravha, H. van Rooyen and T. Coates. 2011. "Looking to the Future: South African Men and Women Negotiating HIV Risk and Relationship Intimacy." Culture, Health \& Sexuality 13 (5): 589-602.

16. Izugbara, C., C. Undie, N. Mudege and A. Ezeh. 2009. "Male Youth and Voluntary Counseling and HIV Testing: The Case of Malawi and Uganda." Sex Education 9 (3): 243-259.

17. Barker, G., C. Ricardo, M. Nascimento, A. Olukoya and C. Santos. 2010b. "Questioning Gender Norms with Men to Improve Health Outcomes: Evidence of Impact.” Global Public Health 5 (5): 539553.

18. Jürgens, R. and J. Cohen. 2007. Human Rights and HIV/AIDS: Now More than Ever - 10 Reasons Why Human Rights Should Occupy the Center of the Global AIDS Struggle. New York, NY: Open Society Institute. http://www.soros.org/initiatives/health/focus/law/ articles_publications/publications/human_20071017/english_nowmore-than-ever.pdf. (p. 7).

19. WHO, UNICEF, \& UNAIDS. 2013. Global Update on HIV Treatment: Results, Impacts, and Opportunities. Geneva, Switzerland.

20. Braitstein, P., A. Boulle, D. Nash, M. Brinkhof, F. Dabis, C. Laurent, M. Schechter, S. Tuboi, E. Sprinz, P. Miotti, M. Hosseinipour, M. May, M. Egger, D. Bangsberg, N. Low and The Antiretroviral Therapy in Lower Income Countries (ART-LINC) Study Group. 2008b. "Gender and the Use of Antiretroviral Treatment in Resource-Constrained Settings: Findings from a Multicenter Collaboration." Journal of Women's Health 17 (1): 47-55 (p. 53).

21. Woman living with HIV cited in Hsieh, A. C., Mburu, G., Garner, A. B., Teltschik, A., Ram, M., Mallouris, C., Penazzato, M., Shaffer, N., Easterbrook, P. J., \& Ball, A. 2014. Community and service provider views to inform the 2013 WHO consolidated antiretroviral guidelines: key findings and lessons learnt. AIDS, 28 Suppl 2, S205-216.

22. Hsieh, A. C., Mburu, G., Garner, A. B., Teltschik, A., Ram, M., Mallouris, C., Penazzato, M., Shaffer, N., Easterbrook, P. J., \& Ball, A. 2014. Community and service provider views to inform the 2013 WHO consolidated antiretroviral guidelines: key findings and lessons learnt. AIDS, 28 Suppl 2, S205-216. (p.10).

23. Noted, for example, in Swaziland (Bacheno et al., 2010); Vietnam (Sethuraman et al., 2011); Tanzania (Arreskov et al., 2010); South Africa (Myer et al., 2012; Clouse et al., 2012; Westreich et al., 2012); Latin America (Kreitchmann et al., 2012); Kenya (Otieno et al., 2010) and Nigeria (Rawizza et al., 2012). See Gay, J., Croce-Galis, M., Hardee, K. 2012.What Works for Women and Girls: Evidence for HIV/ AIDS Interventions.2nd edition. Washington DC: Futures Group, Health Policy Project. Safe Motherhood and Prevention of Vertical Transmission: Postpartum/Gaps: http://www.whatworksforwomen.org/chapters/17-Safe-Motherhood-and-Prevention-of-Vertical-Transmission/sections/49-Postpartum/gaps\#s-820.

24. Ortego et al., 2012 cited in Key Barriers to Women's Access to HIV Treatment: Making 'Fast-Track' a Reality, 2015, UN Women, AVAC, ATHENA, Salamander Trust.

25. Woman living with HIV cited in Hsieh, A. C., Mburu, G., Garner, A.
B., Teltschik, A., Ram, M., Mallouris, C., Penazzato, M., Shaffer, N., Easterbrook, P. J., \& Ball, A. 2014. Community and service provider views to inform the 2013 WHO consolidated antiretroviral guidelines: key findings and lessons learnt. AIDS, 28 Suppl 2, S205-216. (p. 15).

26. Women living with HIV cited in Hsieh, A. C., Mburu, G., Garner, A. B., Teltschik, A., Ram, M., Mallouris, C., Penazzato, M., Shaffer, N., Easterbrook, P. J., \& Ball, A. 2014. Community and service provider views to inform the 2013 WHO consolidated antiretroviral guidelines: key findings and lessons learnt. AIDS, 28 Suppl 2, S205-216. (p.14).

27. Institute of Medicine, National Academy of Sciences (IOM). 2013. Evaluation of PEPFAR. Washington, DC: National Academy Press.

28. Hoffman, S., Wu, Y., Lahuerta, M., Kulkarni, S. G., Nuwagaba-Biribonwoha, H., Sadr, W. E., Remien, R. H., Mugisha, V., Hawken, M., Chuva, E., Nash, D., Elul, B., Team, L., \& the Identifying Optimal Models of, H. I. V. C. C. 2014. Advanced disease at enrollment in HIV care in four sub-Saharan African countries: change from 2006 to 2011 and multilevel predictors in 2011. AIDS, 28(16), 2429-2438.

29. Kanters, S., Nansubuga, M., Mwehire, D., Odiit, M., Kasirye, M., Musoke, W., Druyts, E., Yaya, S., Funk, A., Ford, N., \& Mills, E. J. 2013. Increased mortality among HIV-positive men on antiretroviral therapy: survival differences between sexes explained by late initiation in Uganda. HIV/AIDS - Research and Palliative Care, 5, 111-119.

30. Siu, G. E., Wight, D., \& Seeley, J. 2012. How a masculine work ethic and economic circumstances affect uptake of HIV treatment: experiences of men from an artisanal gold mining community in rural eastern Uganda. Journal of the International AIDS Society, 15 Suppl 1, 1-9. doi: 10.7448/IAS.15.3.17368 (para 1).

31. Siu, G. E., Seeley, J., \& Wight, D. 2013. Dividuality, masculine respectability and reputation: how masculinity affects men's uptake of HIV treatment in rural eastern Uganda. Social Science \& Medicine, 89, 45-52.

32. Mukolo, A., Villegas, R., Aliyu, M., \& Wallston, K. A. 2013. Predictors of late presentation for HIV diagnosis: a literature review and suggested way forward. AIDS and Behavior, 17(1), 5-30.

33. Johnson, L. F. 2012. Access to antiretroviral treatment in South Africa, 2004-2011. The Southern African Journal of HIV Medicine, 13(1), 22-27.

34. Druyts, E., Dybul, M., Kanters, S., Nachega, J., Birungi, J., Ford, N., Thorlund, K., Negin, J., Lester, R., Yaya, S., \& Mills, E. J. 2013. Male sex and the risk of mortality among individuals enrolled in antiretroviral therapy programs in Africa: a systematic review and meta-analysis. AIDS, 27(3), 417-425. (p. 419).

35. Druyts, E., Dybul, M., Kanters, S., Nachega, J., Birungi, J., Ford, N., Thorlund, K., Negin, J., Lester, R., Yaya, S., \& Mills, E. J. 2013. Male sex and the risk of mortality among individuals enrolled in antiretroviral therapy programs in Africa: a systematic review and meta-analysis. AIDS, 27(3), 417-425.

36. Kanters, S., Nansubuga, M., Mwehire, D., Odiit, M., Kasirye, M., Musoke, W., Druyts, E., Yaya, S., Funk, A., Ford, N., \& Mills, E. J. 2013. Increased mortality among HIV-positive men on antiretroviral therapy: survival differences between sexes explained by late initiation in Uganda. HIV/AIDS - Research and Palliative Care, 5, 111-119. doi: 10.2147/HIV.S42521

37. Druyts, E., Dybul, M., Kanters, S., Nachega, J., Birungi, J., Ford, N., Thorlund, K., Negin, J., Lester, R., Yaya, S., \& Mills, E. J. 2013. Male sex and the risk of mortality among individuals enrolled in antiretroviral therapy programs in Africa: a systematic review and meta-analysis. AIDS, 27(3), 417-425. (p. 424)

38. Gari, S., Martin-Hilber, A., Malungo, J. R., Musheke, M., \& Merten, 
S. 2014. Sex differentials in the uptake of antiretroviral treatment in Zambia. AIDS Care, 26(10), 1258-1262.

39. Mills, E.J, C. Bakanda, J. Birungi, K. Chan, R.S. Hogg, N. Ford, J. Nachega and C. Cooper. 2011. "Male Gender Predicts Mortality in a Large Cohort of Patients Receiving Antiretroviral Therapy in Ugada." Journal of International AIDS Society 14 (52).

40. Klausner, J., C. Serenata, H. O’Bra, C. Mattson, J. Brown, M. Wilson, T. Mbengashe and T. Goldman. 2011. "Scale-up and Continuation of Antiretroviral Therapy in South African Treatment Programs, 2005-2009." Journal of Acquired Immune Deficiency Syndromes 56 (3): 292-295

41. Lahuerta, M., Wu, Y., Hoffman, S., Elul, B., Kulkarni, S. G., Remien, R. H., Nuwagaba-Biribonwoha, H., El-Sadr, W., Nash, D., Multi-level determinants of late A. R. T. initiation in sub-Saharan Africa \& Identifying Optimal Models of H. I. V. C. in sub-Saharan Africa Collaboration. 2014. Advanced HIV disease at entry into HIV care and initiation of antiretroviral therapy during 2006-2011: findings from four sub-saharan African countries. Clinical Infectious Diseases, 58(3), 432-441. (p. 435).

42. Nyamhanga, T. M., Muhondwa, E. P., \& Shayo, R. 2013. Masculine attitudes of superiority deter men from accessing antiretroviral therapy in Dar es Salaam, Tanzania. Global Health Action, 6, 21812.

43. Nguyen, N. T., Rasch, V., Bygbjerg, I. C., \& Mogensen, H. O. (2012). Pursuing treatment and moral worth: HIV-infected women in a northern province of Vietnam living with antiretroviral therapy. Journal of the Association of Nurses in AIDS Care, 23(4), 339-349. (p. 343).

44. Kranzer, K., Lawn, S. D., Johnson, L. F., Bekker, L. G., \& Wood, R. (2013). Community viral load and CD4 count distribution among people living with HIV in a South African Township: implications for treatment as prevention. Journal of Acquired Immune Deficiency Syndromes, 63(4), 498-505. (p. 503).

45. Makwiza,I, Schouten, E., Arberle-Grasse, J., Hedt, B., Simwaka, B., Banda, T., Nyirenda, L. 2008. Equity assessment and treatment outcomes in accessing antiretroviral therapy in Malawi. Oral Abstract Session: Mexico City - AIDS 2008: Abstract no. TUAD0101."

Though this is an older reference, it is worth noting that more recent resources continue to lack sex- and age-disaggregated data that allow these distinctions in treatment access to be made.

46. Ferrand, R., S. Lowe, B. Whande, L. Munaiwa, L. Langhaug, F. Cowan, O. Mugurungi, D. Gibb, S. Munyati, B. Williams and E. Corbett. 2010. "Survey of Children Accessing HIV Services in a High Prevalence Setting: Time For Adolescents To Count?” Bulletin of the World Health Organization 88 (6): 428-434. (p. 428).

47. Obare, F., H. Birungi and L. Kavuma. 2011. "Barriers to Sexual and Reproductive Health Programming for Adolescents Living with HIV in Uganda." Population Research \& Policy Review 30 (1): 151-163. (p. 158).

48. Ehrhardt, A., S. Sawires, T. McGovern, D. Peacock and M. Weston. 2009. "Gender, Empowerment and Health: What Is It? How Does It Work?” Journal of Acquired Immune Deficiency Syndromes 51 (Supplement 3): S96-S105.

49. Baral, S., C. Beyrer, K. Muessig, T. Poteat, A. Wirtz, M. Decker, S. Sherman and D. Kerrigan. 2012. "Burden of HIV among Female Sex Workers in Low-income and Middle-income Countries: A Systematic Review and Meta-Analysis." Lancet Infectious Diseases 12 (7): 538-549.

50. Noted, for example, in Turkmenistan (Chariyeva et al., 2011); China (Tucker et al., 2010;Choi et al., 2008); Nigeria (Munoz et al., 2010a); Croatia and Montenegro (Stulhofer et al., 2010); Mozambique (Lafort et al., 2010); Kenya (Okal et al., 2011; Tegang et al., 2010;
FIDA, 2007); India (Karandikar and Prospero, 2010; Swain et al., 2011; Go et al., 2010; Go et al., 2011a;Panchanadeswaran et al., 2010; Erausquin et al., 2011); Russia (Decker et al., 2012); Brazil(Damacena et al., 2011); South Africa (Scorgie et al., 2011; Gould and Fick, 2008); Cambodia (HRW, 2010c); Botswana, Namibia and South Africa (Arnott and Crago, 2009); Serbia (Simic and Rhodes, 2009); Thailand (Decker et al., 2010b; Ratinthorn et al., 2009); Russia (Aral et al., 2003 cited in Stachowiak and Peryshkina, 2007); and globally (UNAIDS, 2011f). See Gay, J., Croce-Galis, M., Hardee, K. 2012. What Works for Women and Girls: Evidence for HIV/AIDS Interventions.2nd edition. Washington DC: Futures Group, Health Policy Project. Prevention for Key Affected Populations: Sex Workers/ Gaps: http://www.whatworksforwomen.org/chapters/7-Prevention-for-Key-Affected-Populations/sections/9-Female-Sex-Workers/ gaps\#s-67

51. WHO, 2014. Consolidated guidelines on HIV prevention, diagnosis, treatment and care for key populations. (p. 61).

52. Arrivillaga, M., M. Ross, B. Useche, A. Springer and D. Correa. 2011. "Applying an Expanded Social Determinant Approach to the Concept of Adherence to Treatment: The Case of Colombian Women Living with HIV/AIDS.” Women's Health Issues 21 (2): 177-183.

53. Hsieh, A. 2013. Understanding the perspectives and experiences of women living with HIV regarding Option B+ in Uganda and Malawi. Global Network of People Living with HIV, International Community of Women Living with HIV/AIDS (ICW) Global, ICW Eastern Africa and Coalition of Women Living with HIV and AIDS.

54. Arrivillaga, M., M. Ross, B. Useche, A. Springer and D. Correa. 2011. "Applying an Expanded Social Determinant Approach to the Concept of Adherence to Treatment: The Case of Colombian Women Living with HIV/AIDS.” Women's Health Issues 21 (2): 177-183.

55. Arnott, J. and A.L. Crago. 2009. Rights Not Rescue: A Report on Female, Male and Trans Sex Workers' Human Rights in Botswana, Namibia and South Africa. NY: Open Society Institute. www.soros. org. (p. 10).

56. Nguyen, N. T., Rasch, V., Bygbjerg, I. C., \& Mogensen, H. O. 2013. Vietnamese women's struggle to access antiretroviral drugs in a context of free treatment. Health Care for Women International, 34(3-4), 209-226. (p. 218).

57. Myer, L., R. Carter, M. Katyai, P. Toro, W. El-Sadr and E. Abrams. 2010. "Impact of Antiretroviral Therapy on Incidence of Pregnancy among HIV-infected Women in Sub-Saharan Africa: A Cohort Study." PLoS Medicine 7 (2): e1000229. www.plosmedicine.org.

58. Myer, L., R. Carter, M. Katyai, P. Toro, W. El-Sadr and E. Abrams. 2010. "Impact of Antiretroviral Therapy on Incidence of Pregnancy among HIV-infected Women in Sub-Saharan Africa: A Cohort Study." PLoS Medicine 7 (2): e1000229. www.plosmedicine.org.

59. Mbonye, M., Nakamanya, S., Birungi, J., King, R., Seeley, J., \& Jaffar, S. 2013. Stigma trajectories among people living with HIV (PLHIV) embarking on a life time journey with antiretroviral drugs in Jinja, Uganda. BMC Public Health, 13, 804; Han, S., J. Zhou, S. Saghayam, S. Vanar, N. Phanuphak, Y.-M. Chen, T. Sirisanthana, C. Lee, S. Pujari, P. Li, S. Oka, V. Saphorn, F. Zahang, T. Merati, M. Law and J. Choi on behalf of The TREAT Asia Observational Database. 2011. "Prevalence and Risk Factors for Lipodystrophy among HIV-infected Patients Receiving Combined Antiretroviral Treatment in the Asia-Pacific Region: Results from the TREAT Asia HIV Observational Database (TAHOD). Endocrine Journal 58 (6): 475-484; Elliott, J., P. Phlong, V. Saphon, J. Kaldor, C. Mean and L. Maher. 2011. "Social Meanings of Adherence to Antiretroviral Therapy in Cambodia." Culture, Health \& Sexuality 13 (06): 685-697.

60. Posse, M., Tirivayi, N., Saha, U. R., Baltussen, R. 2013. The effect 
of Food Assistance on Adherence to Antiretroviral Therapy among HIV/AIDS Patients in Sofala Province, in Mozambique: A Retrospective Study. The Journal of AIDS and Clinical Research 4(3).

61. Aragones-Lopez, C., Perez-Avila, J., Smith Fawzi, M. C., \& Castro, A. 2012. Quality of life of people with HIV/AIDS receiving antiretroviral therapy in Cuba: a cross-sectional study of the national population. American Journal of Public Health, 102(5), 884-892.

62. Tran, B. X. 2012. Quality of life outcomes of antiretroviral treatment for HIV/AIDS patients in Vietnam. PLoS One, 7(7), e41062.

63. Skovdal, M., Campbell, C., Madanhire, C., Mupambireyi, Z., Nyamukapa, C., \& Gregson, S. 2011. Masculinity as a barrier to men's use of HIV services in Zimbabwe. Global Health, 7, 13. doi: 10.1186/17448603-7-13

64. Siu, G. E., Seeley, J., \& Wight, D. 2013. Dividuality, masculine respectability and reputation: how masculinity affects men's uptake of HIV treatment in rural eastern Uganda. Social Science \& Medicine, 89, 45-52. (p. 49).

65. Maskew, M., Brennan, A. T., Westreich, D., McNamara, L., MacPhail, A. P., \& Fox, M. P. 2013. Gender differences in mortality and CD4 count response among virally suppressed HIV-positive patients. Journal of Women's Health - Mary Ann Liebert, Inc., 22(2), 113-120.

66. Siu, G. E., Wight, D., \& Seeley, J. 2012. How a masculine work ethic and economic circumstances affect uptake of HIV treatment: experiences of men from an artisanal gold mining community in rural eastern Uganda. Journal of the International AIDS Society, 15 Suppl 1, 1-9; Siu, G. E., Seeley, J., \& Wight, D. 2013. Dividuality, masculine respectability and reputation: how masculinity affects men's uptake of HIV treatment in rural eastern Uganda. Social Science \& Medicine, 89, 45-52.

67. Mfecane, S. 2012. Narratives of HIV disclosure and masculinity in a South African village. Culture, Health and Sexuality, 14 Suppl 1, S109-121.

68. Skovdal, M., Campbell, C., Madanhire, C., Mupambireyi, Z., Nyamukapa, C., \& Gregson, S. 2011. Masculinity as a barrier to men's use of HIV services in Zimbabwe. Global Health, 7, 13; Hsieh, A. 2013. Understanding the perspectives and experiences of women living with HIV regarding Option B+ in Uganda and Malawi. Global Network of People Living with HIV, International Community of Women Living with HIV/AIDS (ICW) Global, ICW Eastern Africa and Coalition of Women Living with HIV and AIDS.

69. Madiba, S., \& Canti-Sigaqa, V. 2012. Barriers to participate in support groups for people living with HIV: a qualitative study with men receiving antiretroviral treatment in a HIV clinic in Mthatha, South Africa. Global Journal of Health Science, 4(6), 119-128.

70. Siu, G. E., Seeley, J., \& Wight, D. 2013. Dividuality, masculine respectability and reputation: how masculinity affects men's uptake of HIV treatment in rural eastern Uganda. Social Science \& Medicine, 89, 45-52. doi: 10.1016/j.socscimed.2013.04.025; Siu, G. E., Wight, D., \& Seeley, J. 2012. How a masculine work ethic and economic circumstances affect uptake of HIV treatment: experiences of men from an artisanal gold mining community in rural eastern Uganda. Journal of the International AIDS Society, 15 Suppl 1, 1-9. doi: 10.7448/IAS.15.3.17368

71. Groves, A. K., Maman, S., \& Moodley, D. 2012. HIV+ women's narratives of non-disclosure: resisting the label of immorality. Global Public Health, 7(8), 799-811.

72. Ananworanich, J. 2014. State of the ART: HIV Cure - where are we now and where are we going? Plenary Session. 20th International AIDS Conference. Melbourne, Australia. July 20-25; Talley, A. and A. Bettencourt. 2010. "A Relationship-oriented Model of HIV-related Stigma Derived from a Review of the HIV-affected Couples
Literature.” AIDS \& Behavior 14: 72-86; Chen, W., C. Shui, J. Simoni, H. Zhao, M. Bao and H. Lu. 2011. "In Sickness and in Health: A Qualitative Study of How Chinese Women with HV Navigate Stigma and Negotiate Disclosure within their Marriages/partnerships." AIDS Care 23 (Supplement 1): 120-125; Kelley, A., E. Karita, P. Sullivan, F. Katangulia, E. Chomba, M. Carael, J. Telfair, S. Dunham, D. Vwalika, M. Kautzman, K. Wall and S. Allen. 2011. "Knowledge and Perceptions of Couples' Voluntary Counseling and Testing in Urban Rwanda and Zambia: A Cross-Sectional Household Study." PLoS ONE 6 (5): e19573.

73. Simbayi, L, S. Kalichman, A. Strebel, A. Cloete, N. Henda and A. Mqeketo. 2007. "Disclosure of HIV Status to Sex Partners and Sexual Risk Behaviours among HIV-positive Men and Women, Cape Town, South Africa." Sexually Transmitted Infections 83: 29-34.

74. Bott, S., \& Obermeyer, C. 2013. The social and gender context of HIV disclosure in sub-Saharan Africa: A review of policies and practices. SAHARA-J: Jounral of Social Aspects of HIV/AIDS, 10(1), S5-S16. (p. S5).

75. Bott, S., \& Obermeyer, C. 2013. The social and gender context of HIV disclosure in sub-Saharan Africa: A review of policies and practices. SAHARA-J: Jounral of Social Aspects of HIV/AIDS, 10(1), S5-S16.

76. Groves, A. K., Maman, S., \& Moodley, D. 2012. HIV+ women's narratives of non-disclosure: resisting the label of immorality. Global Public Health, 7(8), 799-811.

77. MacGregor, H. and E. Mills. 2011. "Framing Rights and Responsibilities: Accounts of Women with a History of Activism.” BMC International Health 11 (Supplement 3): S7. (p. 4).

78. McGrath, N., Richter, L., \& Newell, M. L. 2013. Sexual risk after HIV diagnosis: a comparison of pre-ART individuals with CD4>500 cells/microl and ART-eligible individuals in a HIV treatment and care programme in rural KwaZulu-Natal, South Africa. Journal of the International AIDS Society, 16, 18048.

79. Onoya, D., Reddy, P. S., Ruiter, R. A., Sifunda, S., Wingood, G., \& van den Borne, B. 2011. Psychosocial correlates of condom use consistency among Isixhosa-speaking women living with HIV in the Western Cape Province of South Africa. J Health Psychol, 16(8), 1208-1220.

80. Onoya, D., Reddy, P. S., Ruiter, R. A., Sifunda, S., Wingood, G., \& van den Borne, B. 2011. Psychosocial correlates of condom use consistency among Isixhosa-speaking women living with HIV in the Western Cape Province of South Africa. J Health Psychol, 16(8), 1208-1220. (p. 1218).

81. Abdool Karim, Q., S. Sibeko and C. Baxter. 2010a. "Preventing HIV Infection in Women: A Global Health Imperative.” Clinical Infectious Disease 50 (Supplement 3): S122-S129. (p. S125).

82. Patel, R., Ratner, J., Gore-Felton, C., Kadzirange, G., Woelk, G., \& Katzenstein, D. 2012. HIV disclosure patterns, predictors, and psychosocial correlates among HIV positive women in Zimbabwe. AIDS Care, 24(3), 358-368.

83. MacGregor, H. and E. Mills. 2011. "Framing Rights and Responsibilities: Accounts of Women with a History of Activism.” BMC International Health 11 (Supplement 3): S7.

84. Allen, C., M. Mbonye, J. Seeley, J. Birungi, B. Wolff, A. Coutinho and S. Jaffar. 2011. "ABC for People with HIV: Responses to Sexual Behavior Recommendations among People Receiving Antiretroviral Therapy in Jinja, Uganda." Culture, Health \& Sexuality 13(5): 529543. (p. 539).

85. Loubiere, S., P. Peretti-Watel, S. Boyer, J. Blanche, S. Abega and B. Spire. 2009. "HIV Disclosure and Unsafe Sex among HIV-infected Women in Cameroon: Results from the ANRS-EVAL Study." Social 
Science \& Medicine 69: 885-891.

86. Mfecane, S. 2012. Narratives of HIV disclosure and masculinity in a South African village. Culture, Health and Sexuality, 14 Suppl 1, S109-121. (p. S115).

87. Mfecane, S. 2012. Narratives of HIV disclosure and masculinity in a South African village. Culture, Health and Sexuality, 14 Suppl 1, S109-121.

88. Siu, G. E., Seeley, J., \& Wight, D. 2013. Dividuality, masculine respectability and reputation: how masculinity affects men's uptake of HIV treatment in rural eastern Uganda. Social Science \& Medicine, 89, 45-52. (p. 48).

89. Jones, D., Kashy, D., Chitalu, N., Kankasa, C., Mumbi, M., Cook, R., \& Weiss, S. 2014. Risk reduction among HIV-seroconcordant and -discordant couples: the Zambia NOW2 intervention. AIDS Patient Care STDS, 28(8), 433-441.

90. Fauci, A. 2009. "The Future of Global HIV Treatment and Prevention." Presentation at the Center for Strategic and International Studies. Washington, DC. December 14; SMART - The Strategies for Management of Antiretroviral Therapy (SMART) Study Group. 2006. "CD4+ Count-Guided Interruption of Antiretroviral Treatment.” New England Journal of Medicine 355 (22): 2283-2296.

91. WHO. 2010. "Antiretroviral drugs for treating pregnant women and preventing HIV infection in infants: recommendations for a public health approach. - 2010 version." Geneva, Switzerland: WHO. (p. 47).

92. WHO. 2014. HIV prevention, diagnosis, treatment and care for key populations: Consolidated guidelines. Geneva, Switzerland: WHO.

93. WHO. 2014. HIV prevention, diagnosis, treatment and care for key populations: Consolidated guidelines. Geneva, Switzerland: WHO.

94. Collazos, J., V. Asensi and J. Carton. 2007. "Factors Associated with Poor Immunologic Responses Despite Viral Suppression in Markedly Immunosuppressed Patients." AIDS Patient Care \& STDs 21 (6): 378-384; Fardet, L., M. Mary-Krause, I. Heard, M. Partisani and D. Costagliola, for the French Hospital Database on HIV. 2006. "Influence of Gender and HIV Transmission Group on Initial Highly Active Antiretroviral Therapy Prescription and Treatment Response." HIV Medicine 7: 520-529; Currier et al., 2010 cited in Department of Health and Human Services (DHHS). 2011. Guidelines for the Use of Antiretroviral Agents in HIV-1-infected Adults and Adolescents. Washington, DC: DHHS.

95. Clark et al., 2005 cited in Department of Health and Human Services (DHHS). 2011. Guidelines for the Use of Antiretroviral Agents in HIV-1-infected Adults and Adolescents. Washington, DC: DHHS; Hawkins et al., 2011 cited in Johannessen, A. 2011. "Are Men the Losers of the Antiretroviral Scale-up?" AIDS 25: 1225-1226.

96. Firnhaber, C., L. Smeaton, B. Grinszstejn, Y. chen, U. Lalloo, S. Faesen, W. Samaneka, J. Lama, A. Rana and T. Campbell. 2012. "Sex Association with ARV Efficacy Outcomes in a Prospective Ran- domized Clinical Trial of ART in Diverse Multinational Settings: The ACTG PEARLS Study." Oral Abstract \#89. 19th Conference on Retroviruses and Opportunistic Infections. Seattle, Washington. March 5-8.

97. Kipp, W., A. Alibhai, L. Duncan-Saunders, A. Senthilselvan, A. Kaler, J. Konde-lule, J. Okech-ojony and T. Rubaale. 2010. "Gender Differences in Antiretroviral Therapy Treatment Outcomes off HIV Patients in Rural Uganda." AIDS Care 22 (3): 271-278.

98. Nunes, A., I. Melo, A. Silva, L. Rezende, P. Guimaraes and M. Silva-Vergara. 2010. "Hospitalization for HIV/AIDS: Differences between Sexes." Gender Medicine 7 (1): 28-38.

99. Gandhi et al., 2004, Floridia et al., 2008, Ofotokun et al., 2007 cited in Department of Health and Human Services (DHHS). 2011. Guidelines for the Use of Antiretroviral Agents in HIV-1-infected Adults and Adolescents. Washington, DC: DHHS. (p. 104).

100. Hasan, S., S. Keong, C. Choong, S. Ahmed, T. Ching, M. Anwar, K. Ahmadi and M. Babar. 2011. "Patient-reported Adverse Drug Reactions and Drug-drug Interactions: A Cross-sectional Study on Malaysian HIV/AIDS Patients." Medical Principles \& Practice 20: 265-270.

101. d'Arminio Monforte, A., Anderson, J., \& Olczak, A. 2013. What do we know about antiretroviral treatment of HIV in women? Antiviral Therapy, 18 Suppl 2, 27-34. (p. 30).

102. d'Arminio Monforte, A., Anderson, J., \& Olczak, A. 2013. What do we know about antiretroviral treatment of HIV in women? Antiviral Therapy, 18 Suppl 2, 27-34.

103. Mosha, F., Muchunguzi, V., Matee, M., Sangeda, R. Z., Vercauteren, J., Nsubuga, P., Lyamuya, E., \& Vandamme, A. M. 2013. Gender differences in HIV disease progression and treatment outcomes among HIV patients one year after starting antiretroviral treatment (ART) in Dar es Salaam, Tanzania. BMC Public Health, 13, 38.

104. Taylor-Smith et al., 2010 cited in Institute of Medicine, National Academy of Sciences (IOM). 2013. Evaluation of PEPFAR. Washington, DC: National Academy Press.

105. Heidari, S., E. Gruslin, R. Kort, C. Roll, D. Gilden and the IAS-ILF Reference Group and Advisory Group. 2010. Environmental Scan: Mapping HIV Research Priorities for Women and Children. Geneva, Switzerland: International AIDS Society. www.iasociety.org. (p. 4).

106. d'Arminio Monforte. L. Gonzalez, A. Haberl, L. Sherr, W. Ssanyu-Sseruma, S. Walmsley on behalf of Women for Positive Action. 2010. "Better Mind the Gap: Addressing the Shortage of HIV-positive Women in Clinical Trials.” AIDS 24: 1091-1094.

107. Soon, G. G., Min, M., Struble, K. A., Chan-Tack, K. M., Hammerstrom, T., Qi, K., Zhou, S., Bhore, R., Murray, J. S., \& Birnkrant, D. B. 2012. Meta-analysis of gender differences in efficacy outcomes for HIV-positive subjects in randomized controlled clinical trials of antiretroviral therapy (2000-2008). AIDS Patient Care and STDs, 26(8), 444-453. 
The Evidence Project is led by the Population Council in partnership with INDEPTH Network, International Contact Us Planned Parenthood Federation, Management Sciences for Health, PATH, Population Reference Bureau, Contact Us and a University Research Network. Other partners are FHI360, Meridian Group International, Inc., and What Works Association.

The Evidence Project 4301 Connecticut Ave. Suite 4301 Washington, DC 20008 www.evidenceproject.popcouncil.org
The Evidence Project is made possible by the generous support of the American people through the United States Agency for International Development (USAID) under the terms of cooperative agreement no. AIDOAA-A-13-00087.

What Works for Women \& Girls is supported by the U.S. President's Emergency Plan for AIDS Relief (PEPFAR) and is being carried out under the auspices of the USAID-supported Evidence Project and What Works Association, Inc. For more information, please visit www.whatworksforwomen.org or email mcrocegalis@gmail.com.

The information provided in this document is not official U.S. Government information and does not necessarily represent the views or positions of the U.S. Agency for International Development. 